\title{
Sudden Deaths in Hospital
}

Psychiatric hospital staff usually know when one of their in-patients dies in their hospital (but see 'In-patients sometimes kill themselves'). However, if an in-patient has died elsewhere, in an intensive care unit for instance, this is not quite so easy; when death occurs at home, possibly after discharge from ward or clinic, the psychiatrist may only hear of it by chance. Mrs Elizabeth King describes four ways in which these deaths can be traced. The two papers printed here are part of the fruits of a College Working Party on
Sudden Deaths in Hospital. We want to encourage more study of suicide, and more follow-up of ex-patients, and the Research Committee will be happy to give advice on individual schemes, if requested, and also to welcome additional participants in a multicentre confidential study of sudden deaths, whether due to accident, drug errors or suicide. Anyone interested should write to $\mathrm{Dr}$ J. L. Crammer, Dr Sheila Mann or Miss Jane Boyce at the College.

\section{In-Patients Sometimes Kill Themselves}

\section{J. L. Crammer, Reader in Biological Psychiatry, Maudsley Hospital}

If the Health Service were perfect there would be no suicides among hospital patients. The first aim of all doctors and nurses is to preserve life, and patients are admitted to hospital in part so that they will not harm or kill themselves. Yet every year over 100 , perhaps 200 or more people in the UK, deliberately end their lives while receiving in-patient psychiatric care. The exact number is not known, partly because of the way the statistics are collected, and partly because of a pall of secrecy spread over such deaths.

The distribution of these deaths across the country is curious. Some hospitals have none, others have one or two in most years. Some consultants never have a suicide among all their in-patients in years of practice, others are not so lucky. In over 20 years as a consultant I can only remember two of mine, both women, who killed themselves at home when I mistakenly allowed them out on weekend leave. But I have known of others in my hospitals.

Distribution of suicides over the years is irregular, too. It looks as though a hospital may now and then suffer a kind of micro-epidemic for a year, a sudden little flurry of deaths. The Warlingham inquiry reported 0-2 suicidal in-patient deaths in hospital per year 1960-1973, but eight deaths in 1974 the reason for the inquiry. Does the accomplished death of one person encourage other patients to do likewise? Or is it the arrival of an inexperienced doctor who misjudges situations? Or a change in the way the institution is run?

Faced with the fact of a suicide we may feel sad, guilty, and a failure. Our inclination is to judge that the death was inevitable or excusable, and we do not want to report it, discuss it, or analyse it, but pass quickly to the next business. Yet patients' suicidal urges are rarely consistently powerful over long periods. They mostly fluctuate quite rapidly, they are often directed to particular suicidal methods, and if these are unavailable suicide is much less likely. The final act is often the outcome of a sudden impulse in propitious surroundings, and death was not really inevitable until the surroundings were just right.

Here are three cases from my experience. The first took place in an acute admission ward of 20 women. The ward was staffed that morning by a Sister and a student nurse. The consultant interviewed a depressed patient in the office and then conferred with the Sister. Thirty minutes later the patient was noticed to be absent from the ward sitting-room and was found drowned in the bath. I do not know what analysis, if any, of these events took place, but clearly the ward staffing needed reconsideration; perhaps training could have been improved, bathroom doors kept locked, and maybe the doctor's assessments and advice on management needed revision.

The second started in an acute admission ward for men on a fine midsummer morning. The ward was a separate building in the hospital grounds, and the outer door was kept locked at night. At 5 a.m. a man got up and asked the night nurse if he could go and phone his wife from a call box in the grounds. The nurse obligingly unlocked the door and let him out, whereupon he went over to other buildings, climbed an outside fire escape and threw himself down onto a concrete roadway. Was this death inevitable, or a consequence of over-permissiveness, or a failure of day staff to communicate effectively to night staff?

The third was in a mental hospital long-stay ward. The hospital had staffing difficulties, and in some wards of 20 or 30 patients there was no night nurse but the patients were put to bed, the wards locked, and they were left to look after themselves till morning. One morning a man of about 35 with chronic schizophrenia for ten years or so was found hanging in a lavatory. Was this inevitable? Or should patients never be left totally unsupervised for long periods, and this be repeatedly drawn to the attention of administrators?

The Coroner is there primarily to decide whether a death was accident, suicide or murder. He is not there to go into 
details of care and organization (he is not staffed or trained to do so) and he is often on the side of the doctors and does not want to embarrass them. Some Coroners make recommendations to hospitals, many do not; they are more likely to do so if sitting with a jury, and particularly if there have been several suicides in the one institution. But only those really in the day-to-day know - the nurses and doctors on the wards, the administrators, the secretaries and telephonists, social workers, general practitioners and so on - can trace out the patient's route from home to death.

Communications between professionals, the timing of visits, the frequency of assessments and reassessments, the use of treatments, the staffing, the buildings - somewhere along the line, there may have been a failure which could have been avoided yet has led on to a death. A hospital inquiry here may point to the possibility of improvements, which may benefit others. Occasionally it may provide evidence to persuade the authorities to increase specific finance or staffing. It is better for the hospital and its patients to clean out the dark cupboards regularly than to wait for the Coroner's criticism or a public inquiry.

I recently wrote round to 30 hospitals scattered over the UK, mostly outside London, to ask people I knew in them what happened when they had an in-patient suicide. Was there any regular procedure? Was the death analysed by the consultant only, by the ward team, by the nursing hierarchy, the senior medical staff committee, the district management team ... who? Were they aware of any changes in use of staff or buildings, or in administration, as a result of analysis of a suicide? I am very grateful to my friends for their replies, some of which were supplemented with detailed letters. At one extreme was the story told by a consultant in a hospital of some standing. He had had a man as an inpatient and out-patient over several years. Later this man was readmitted, but under a different consultant in a different ward. My friend met him by chance on several occasions in the grounds and chatted with him! He writes: 'Eventually as I saw him no more I assumed he was discharged home. Three months later a friend of my wife's told her that she had heard from the patient's wife's dentist that the patient had killed himself in hospital. I found this was correct.' On the other hand at another hospital 'a list of all known suicides (in- and out-patient) is made by the hospital administrative staff and is the subject of a six-monthly meeting of representatives of all the professions involved to monitor the deaths. At every Division meeting there is time set aside for the reporting and discussion of "unexpected deaths arising to patients".' The hospital secretary, the chief nursing officer and the clinical team are expected to carry out inquiries when any suicide occurs, and the first two prepare reports. Following an unfortunate death, admissions procedures were reformed.

Taking the $\mathbf{3 0}$ replies as a whole, about a quarter said there was no procedure for considering a death, but two added that if a Coroner criticized, they would, of course, respond. The majority thought that a discussion meeting of the unit or ward team was the usual procedure, including doctors, nurses, and possibly community workers, and one specified that the responsible medical officer would attend. However, the purpose of the meeting varied. Two thought of it as allaying staff distress (in one or two it was quite informal and casual), and in only a few hospitals was it linked to communication with the hospital management team, and in some cases to a senior medical staff meeting. In two hospitals the Psychiatric Division reviewed all unexpected deaths, in another four the psychiatric management team reviewed all 'untoward incidents' and the medical and nursing members followed this up with their own analysis. Where management was involved, changes could follow. Three hospitals reported the blocking of stair wells. Windows received toughened glass or bars, bath taps were removed and held by the nurse in charge, lavatory tanks were lowered after a hanging. Changes were not confined to buildings. New guidelines were issued to nurses for the observation of disturbed patients in one hospital, for the search for missing patients in another, for revised admission procedures in a third. Methods of dealing with staff shortages were reviewed, but several correspondents expressed impotent gloom on this subject.

In response to a micro-epidemic of deaths at a teaching hospital any 'violent death. suicide, or accident results in a medical audit by consultant staff, a nursing inquiry, an administrative inquiry, and reports to the District Management Team' with changes in staff distribution, and in use of wards, new nursing procedures and increased security measures-door alarms, for instance'. Is it necessary to wait for a micro-epidemic before setting up such action?

An in-patient is someone for whom the hospital staff have accepted responsibility, and this responsibility continues when the patient is allowed out on leave, or goes missing, until he or she is discharged. Where the patient actually dies is not important. In-patient suicides include those who die elsewhere other than in the hospital building - for instance, while at home on leave, or in the countryside within 24 hours of absconding, or in an intensive care unit to which they have been transferred after discovery of self-poisoning. The circumstances of granting leave or of absconding may be important, the exchange of information between staff, the function of telephones and bleeps, the handling of drugs, the distribution of staff, and many other matters in the efficient carrying out of responsibilities to the patient. Because the responsibility involves many people in different occupations it is a whole hospital matter, and the hospital management team ought always to inquire into any in-patient death. They ought to expect a report from the consultant and nursing officer most closely concerned in every case, derived from a discussion meeting of ward staff and others concerned with the particular patient-including secretaries and porters where appropriate. The reason for this is that the death becomes educative. The staff become more closely identified 
with the hospital's purpose, each person appreciates his own role better, errors and omissions can be identified and corrected and better working procedures introduced.

In-patient suicides are fortunately rare. Their irregularity of appearance suggests that they may quite often be the consequence of some lapse in the proper working of a ward or unit. Therefore it is worth examining the detailed circumstances of every such death to see whether the ward and hospital have functioned perfectly. Correctible imperfections may be revealed, and staff morale enhanced, in which case the death will have brought a gain.

\title{
Identifying Out-Patients and Ex-Patients Who Have Died Suddenly
}

\author{
Euzabeth KIng, Research Assistant, Department of Psychiatry, University of Southampton
}

In a study to investigate how many ex-patients died since 1974 from sudden or violent causes among all the residents in the catchment area of a general hospital psychiatric unit, the identification of the ex-patients was completed with minimum use of the local coroner as a source of names. Since much of the information available from coroners is available elsewhere, and in view of the considerable pressure of work on coroners, it was felt that alternative sources of information should initially be explored. Three alternative sources, available from death registration procedures, are described and the usefulness of the data available from each source discussed.

By law, every death occurring in England or Wales, and its cause, must be registered in the District in which it occurred, and statutory regulations prescribe what details must be recorded at the time of registration. These particulars, together with the cause of death as stated by the doctor certifying death, or by the coroner to whom the death was reported, are recorded on a Draft entry form (Form 310 ) and verified as correct by the person registering the death, usually a relative, who receives one copy and another is made in the Death Register. Form 310 is posted to the Vital Statistics Branch of the Office of Population Censuses and Surveys (OPCS) where the information is coded and stored on magnetic tape (Mortality File). Under the NHS Acts, a photocopy of all the new entries in the Death Register is sent at the end of each week to the Medical Officer of the District Health Authority (DHA) in which the Registration District or Sub-District lies. Community Health Centres also receive photocopies and permission can be obtained to inspect them.

The information recorded at death registration and held by OPCS and DHAs can be obtained in the form of photocopies, and in addition, a printout of the coded information on the Mortality File is available from Regional Health Authorities. The Mortality File contains all the information recorded on the Death Register relating to residents of the Region except the name of the deceased.

\section{The four sources}

1. Coroners' records

Populations for mortality studies into unnatural deaths have usually been identified from coroners' records since all

TABLE I

Information available as a result of death registration procedures

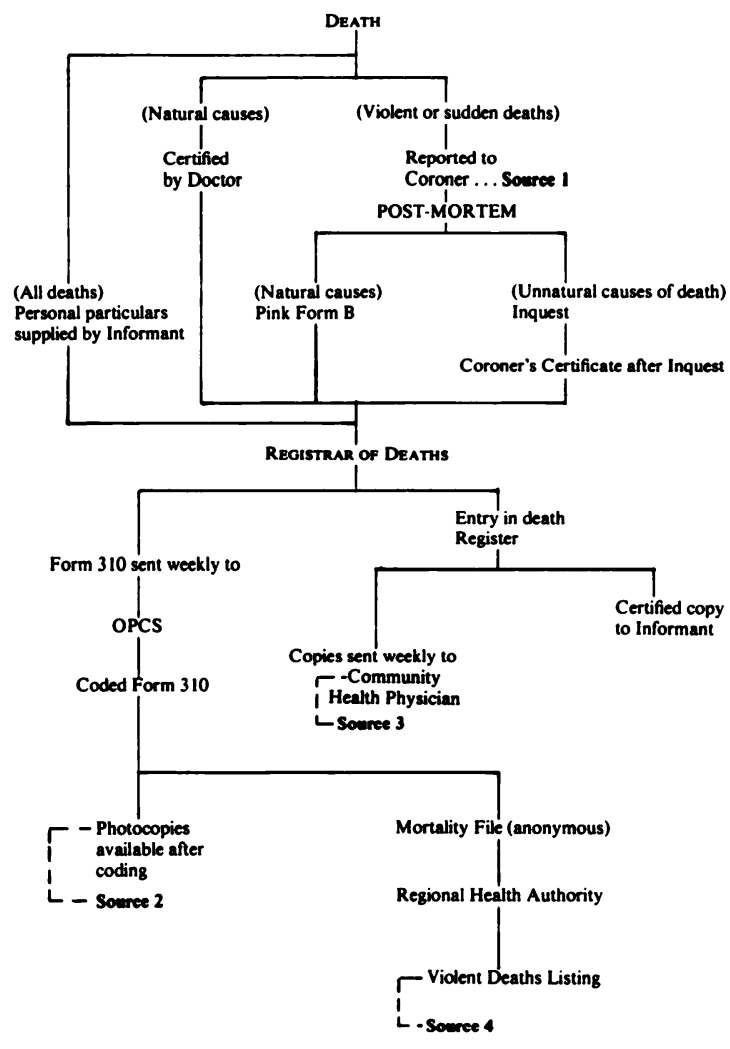

